\title{
Impact of Retailer's Vertical and Horizontal Fairness Concerns on Manufacturer's Online Channel Mode
}

\author{
Xuemei Zhang $\mathbb{D}^{1,2}$ Chenhao Ma, ${ }^{1}$ Haoran Chen, ${ }^{1}$ and Guohu Qi $\mathbb{D}^{1,2}$ \\ ${ }^{1}$ Business School, Fuyang Normal University, Fuyang, Anhui 236037, China \\ ${ }^{2}$ Anhui Provincial Key Laboratory of Regional Logistics Planning and Modern Logistics Engineering, Fuyang Normal University, \\ Fuyang, Anhui 236037, China \\ Correspondence should be addressed to Guohu Qi; qiguohu@163.com
}

Received 23 November 2020; Revised 3 February 2021; Accepted 16 February 2021; Published 28 February 2021

Academic Editor: Rodica Luca

Copyright (c) 2021 Xuemei Zhang et al. This is an open access article distributed under the Creative Commons Attribution License, which permits unrestricted use, distribution, and reproduction in any medium, provided the original work is properly cited.

\begin{abstract}
This paper investigates a dual-channel supply chain consisting of a manufacturer and a retailer, where the retailer exhibits vertical and horizontal fairness concerns. The manufacturer or the retailer direct selling and e-commerce platform agency selling modes are employed to characterize the impact of retailer's fairness concerns on the online channel mode strategy. Results show that the retailer's fairness concerns only affect the wholesale price and online channel mode strategy. Without the retailer's fairness concerns, the manufacturer direct selling mode is the best strategy for the manufacturer, which harms the retailer's utility. With the retailer's fairness concerns, the manufacturer may choose the manufacturer direct selling or e-commerce platform agency selling mode. When the fairness concern parameters meet a certain range, the e-commerce platform agency selling mode strategy is better for the supply chain members, which can solve the interest conflict between supply chain members. These research findings help dual-channel supply chain members understand how to choose the channel structure strategy to balance the supply chain members' interests by considering fairness concerns.
\end{abstract}

\section{Introduction}

With the rapid development of e-commerce, online consumption has shown exponential increase [1]. For example, in April 2020, the $45^{\text {th }}$ China Statistical Report on Internet development shows that, up to March 2020, the number of Internet users in China is 904 million, and mobile network payments reach 765 million users [2]. In recent Tmall "double eleven" shopping festival in 2020, the turnover was more than $\$ 77.54$ billion in just one day. More and more consumers choose online consumption, and offline stores are challenged. Facing pressure from this change, more and more manufactures/retailers have begun to develop an online direct channel in addition to their existing traditional offline channel $[1,3]$. Dual-channel structure is widely and successfully employed in practice, which brings huge benefits to enterprises [4]. For example, manufacturers such as Apple, Nike, and Dell have opened online shops through their own websites or through the third-party Internet platforms [5, 6]. Some retailers such as Wal-Mart, Suning, and Gome have opened online shops for achieving onlineoffline channel integration $[7,8]$. There are a variety of online channel operation modes, such as manufacturer online direct selling mode, retailer online direct selling mode, and e-commerce platform agency selling mode $[9,10]$. Therefore, how to choose the online channel operation mode and leverage the full channel strengths of the online and offline channels has become a key to enhance the operational efficiency of the dual-channel supply chain [11-14].

In competitive markets today, channel conflict is becoming more and more serious. For example, in 2015, certain US suppliers sought legal recourse against Wal-Mart Stores [15]. Channel conflict issues have received attention in economic, marketing, and operations management [15]. The aforementioned research assumed that relevant enterprises are completely rational, which are treated as the "rational economic man." In reality, the firms often exhibit 
bounded rationality and demonstrate different social preferences such as fairness concerns [16], which is one of the most critical issues related to supply chain operation. In practice, supply chain members often compare their profit with that of their closest member [17]. Specifically, in the market dominated by sales, the retailer's fairness concern behavior is more prominent [18]. In today's industrial practice, retailers' vertical fairness concerns about manufacturer's profit are widespread [19]. With the rapid development of e-commerce platform agency selling mode, retailers' horizontal fairness concerns about e-commerce platform's profit do fluence supply chain members' decisions and channel structure mode [20]. Therefore, to promote the retailer's cooperation with the manufacturer, it is necessary for the manufacturer to take the retailer's vertical and horizontal fairness concerns into account [21]. In this research, we incorporate the retailer's fairness concerns into a game model of dual-channel supply chain to examine their impacts on the optimal operation decisions and manufacturer's online channel mode.

More specifically, considering the retailer's vertical and horizontal fairness concerns, we will structure a game theoretic model in a dual-channel supply chain to examine a manufacturer's optimal online channel mode. In the dualchannel supply chain, on one hand, the manufacturer sells its products to a retailer wholesale, and then the retailer sells these products to consumers through traditional offline channel. On the other hand, the manufacturer chooses one online channel mode to operate. Three online channel modes are examined: (1) manufacturer direct selling mode (model $D),(2)$ retailer direct selling mode (model $R$ ), and (3) e-commerce platform agency selling mode (model $A$ ). Under the two direct selling modes, the retailer's vertical fairness concern about the manufacturer's profit is considered, and under the agency selling mode, the retailer's vertical fairness concern about the manufacturer's profit and its horizontal fairness concern about e-commerce platform's profit are all considered. The manufacturer's objective is to choose an online channel mode to maximize its profit. This research attempts to address the following three questions:

(1) How to derive the optimal pricing decision, demand, profit, and utility for the dual-channel supply chain with the retailer's fairness concerns under the $D, R$ and $A$ models based on a Stackelberg dynamic game?

(2) What is the impact of the retailer's vertical and horizontal fairness concerns on the performance of the dual-channel supply chain and the manufacturer's online channel mode?

(3) What are the applicable conditions for each online channel mode and how to choose the optimal online channel mode for the manufacturer by considering the retailer's fairness concerns?

The remainder of this paper is organized as follows. Section 2 reviews the related literature. In Section 3, the problem description and model assumptions of the proposed model are illustrated. Section 4 examines the equilibrium results for the $D, R$ and $A$ models based on the
Stackelberg dynamic game. Sensitive and comparative analyses of equilibrium results are presented, and an optimal online channel mode is put forward in Section 5. In Section 6, Numerical illustration is used to evaluate the impact of the retailer's fairness concerns. Section 7 discusses the results, concludes the paper, and presents future research directions. All mathematical proofs are provided in the Appendix.

\section{Literature Review}

Based on the research questions in this paper, we draw two main streams of literature that are relevant to our study: the channel structure strategy of dual-channel supply chains and the effect of fairness concerns on supply chains.

2.1. Channel Structure Strategy of Dual-Channel Supply Chains. A critical issue in the dual-channel supply chain is the channel structure strategy, which has attracted considerable attention in academia and practice. Most of the existing studies investigate the pricing, service issues under the dual-channel structure of manufacturers' online direct selling mode, and limited research has been carried out regarding the online channel structure strategy [22-26]. For instance, Yang et al. [27] examined impacts of environmental responsibility and green level on dual-channel structure and found that there exists an interaction between dual-channel structure choice and green level decision. Huang et al. [28] studied selling channel strategies in luxury brand's supply chains with gray markets and showed that gray marketing can benefit authorized members by mitigating double marginalization. Zhang et al. [29] investigated the effect of a manufacturer's encroachment by introducing an online channel and showed that both the manufacturer and retailer can benefit from the manufacturer's encroachment under certain conditions. Lu and Liu [30] examined the effects of e-commerce channel entry on the profitability and found that the manufacturer may be worse off selling in a dual-channel distribution structure if e-channel efficiency is low. Pu et al. [31] investigated the manufacturer's online distribution strategies: direct selling, reselling, or agency selling. Abhishek et al. [32] examined when should they use an agency selling format instead of using the more conventional reselling format? And they found that the agency selling is more efficient than reselling and leads to lower retail prices. Shi et al. [33] studied the vertical and horizontal competitions among manufacturers, online retailers, and physical stores via considering different power structures of the supply chain. To identify the optimal channel format for trade-in, Xiao et al. [34] constructed traditional retail channel model and dual-channel model under two scenarios: without trade-in and with trade-in. Zhang and Hezarkhani [35] developed a model to analyze a manufacturer's channel selection decision among three channel strategies, i.e., a direct-channel strategy, a retailchannel strategy, and a dual-channel strategy consisting of both direct and retail channels. Jia and $\mathrm{Li}$ [36] studied a closed-loop supply chain involving e-retailer's online marketplace, and self-run shop, which are available options for 
upstream manufacturer to market new and remanufactured products. Sun et al. [37] investigated the channel strategies for online retailers regarding whether to introduce web showrooms in the face of consumer webrooming behavior. The aforesaid research indicates that the channel structure strategy is extremely important for supply chain operation. But it remains an unsettled issue as to how does the fairness concern behavior of supply chain members affect channel structure strategy selection.

\subsection{Effect of Fairness Concerns on Supply Chains. An in-} creasing number of researchers have focused on the effect of fairness concerns on supply chains [38-40]. Qin et al. [41] conducted experimental research through data to explore the impact of fairness concerns on the operation of dualchannel supply chains. Based on the double helix supply chain model, Pan et al. [15] studied the impact of fairness concerns on the supply chain dominated by a retailer and two manufacturers on the basis of a two-echelon supply chain model. Given the retailer's distributional fairness concerns, Zheng et al. [16] investigated the optimal/equilibrium decisions and profits under five noncooperative and cooperative game models and focused on how to allocate maximum profit in a centralized setting. Allender et al. [42] studied how price obfuscation affects consumer fairness concerns, consumer demand, and equilibrium pricing strategies. Toktaş-Palut [43] investigated the impact of fairness concerns on an integrated contract for coordinating a three-stage green forward and reverse supply chain. Adhikari and Bisi [44] investigated the impact of the fairness concern of the supply chain members on the greening and pricing decisions. Liu et al. [45] investigated the order allocation of logistics service supply chain that consists of one logistics service integrator and two competing functional logistics service providers who participate in the allocation successively. Nie and $\mathrm{Du}[46]$ investigated quantity discount contracts in a dyadic supply chain that consists of one supplier and two retailers with fairness concerns. Li et al. [19] introduced retailer's fairness concerns into the encroachment problem and explored its impact and showed that encroachment may be detrimental to the supplier when the retailer has strong fairness concerns and a significant marketing advantage. These studies reveal that fairness concerns have a significant impact on the performance of supply chain operation. This motivates us to consider the effect of fairness concerns on channel structure strategy. Especially, we incorporate the vertical and horizontal fairness concerns into a dual-channel supply for selecting channel structure strategy.

Different from the above literature research, this paper studies the influence of retailer's vertical and horizontal fairness concerns on the decision of dual-channel supply chain members and the online channel strategy for manufacturers. Considering the three channel mode strategies, manufacturer direct selling, retailer direct selling, and e-commerce platform agency selling, this paper constructs three dynamic game models of dual-channel supply chain with retailer's vertical and horizontal fairness concerns. And whether the retailer's fairness concern behavior will change the optimal decision of supply chain members and the manufacturer's online channel mode strategy is analyzed. The main contributions of this paper are as follows:

(1) Exploring whether the manufacturer chooses retailer direct online selling mode or e-commerce platform agency selling mode with retailer's fairness concerns, and the decision-making of a dual-channel supply chain is investigated under different online channel structure modes

(2) Structuring three dynamic models to analyze the effect of retailer's vertical and horizontal fairness concerns on decisions of a dual-channel supply chain and manufacturer's online channel structure mode strategy

(3) Putting forward a method of choosing online channel structure mode strategy, and an optimal online channel structure mode strategy is proposed by considering the retailer's fairness concerns

\section{Problem Description and Model Assumptions}

We consider a dual-channel supply chain consisting of a manufacturer and a retailer or e-commerce platform. For the traditional offline channel, the manufacturer sells the products to a retailer at wholesale price $w$, and then the retailer sells the products to consumers at retail price $p_{r}$. For the online channel, the manufacturer can build the online channel by itself to sell the products to consumers, which is called manufacturer direct selling mode (model $D$ ). The retailer can also build the online channel to sell the products to consumers, which is called retailer direct selling mode (model $R$ ). The manufacturer can also directly sell the products to consumers through the e-commerce platform (model $A$ ), which only takes the commission fee per unit product from the manufacturer, i.e., $s(0<s<1)$ proportion of profit obtained by selling the products through the e-commerce platform. In the three models, the retail price is $p_{e}$. The dual-channel supply chain structure with three online channel modes is shown in Figure 1. In the dualchannel supply chain, the manufacturer and the retailer play a manufacturer-dominate Stackelberg game. Because the operation cost of online and offline channels and other costs do not affect the result of online channel mode strategy selection and only affect the threshold value for online channel mode strategy, for the convenience of analysis, following $\mathrm{Pu}$ et al. [31], the manufacturer's product production cost, transportation cost, operation costs of online and offline channels, and e-commerce platform cost are assumed to be zero.

In the dual-channel supply chain, following Liu et al. [47] and Li et al. [48], the market demand is assumed to be constant, and the size of the market is 1 . The proportion of offline channel is assumed to be $\alpha(0<\alpha<1)$, and the proportion of online channel is assumed to be $1-\alpha$. The market demand is assumed to be a linear function of price, 


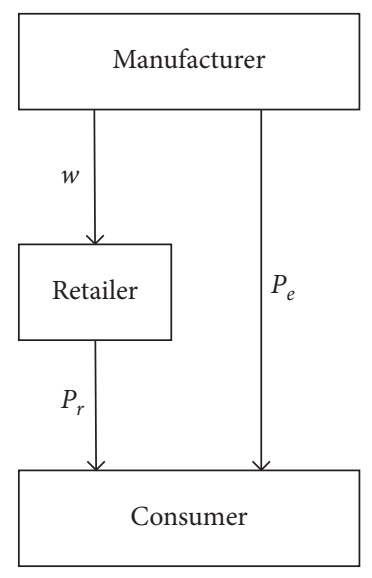

(a)

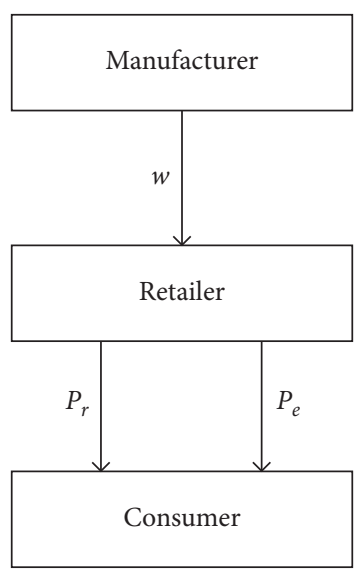

(b)

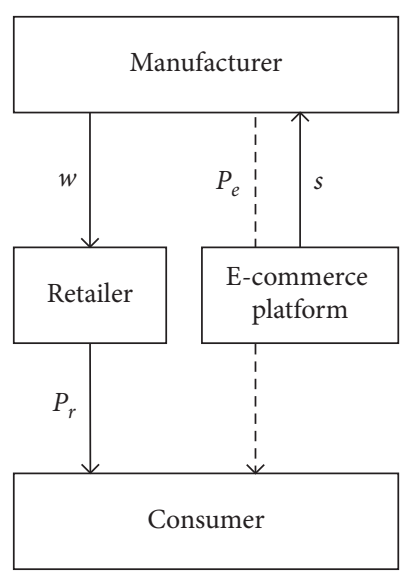

(c)

Figure 1: Structure of three online channel modes in a dual-channel supply chain, (a) model $D$, (b) model $R$, (c) model $A$.

and then the market demands in each channel are assumed to be $D_{r}=\alpha-\beta p_{r}$ and $D_{e}=1-\alpha-\beta p_{e}[17,49,50]$.

Denote $\pi_{m}, \pi_{r}, \pi_{e}$ and $U_{r}$ as the profits of the manufacturer, retailer, e-commerce platform, and retailer's utility, respectively. Under the manufacturer or retailer direct selling mode, the retailer's vertical fairness concerns about the manufacturer's profit are considered, and the utility function is assumed to be $U_{r}=\pi_{r}-\lambda\left(\pi_{m}-\pi_{r}\right)$ $[15,16,46,51,52]$, where $\lambda(0<\lambda<1)$ is the vertical fairness concern coefficient. Under the e-commerce platform agency selling mode, the retailer's vertical fairness concerns about the manufacturer's profit and the horizontal fairness concerns about e-commerce platform's profit are considered, and the utility function is $U_{r}=\pi_{r}-\lambda\left(\pi_{m}-\pi_{r}\right)-\gamma\left(\pi_{e}-\pi_{r}\right)$ $[40,46,53]$, where $\gamma(0<\gamma<1)$ is the horizontal fairness concern coefficient.

The superscripts $D, R$ and $A$ indicate the models $D, R$ and $A$, and "*" is added to the superscript of the optimal values in each model. To analyze the impact of the retailers' fairness concerns on online channel mode strategy, setting $\lambda=0$ and $\gamma=0$, we have the optimal results without the retailer's fairness concerns. Without the retailer's fairness concerns, we add ND, NR and NA to the superscript of these results.

\section{Model Formulations}

In this part, we derive the equilibrium results for the three dynamic models $D, R$, and $A$ and analyze the impact of the retailer's fairness concerns on these optimal decisions in the dual-channel supply chain.

4.1. Manufacturer Direct Selling Mode (Model D). In model $D$, the retailer's vertical fairness concerns about the manufacturer's profit are considered. The manufacturer firstly determines the wholesale price $w^{D}$ and retail price $p_{e}^{D}$ of online channel to maximize its profit. And then, the retailer determines the retail price $p_{r}^{D}$ of offline channel to maximize its utility. The manufacturer and the retailer play a Stackelberg game, and the optimization model is formulated as

$$
\begin{array}{ll}
\max _{w^{D}, p_{e}^{D}} & \pi_{m}^{D}=w^{D}\left(\alpha-\beta p_{r}^{D}\right)+p_{e}^{D}\left(1-\alpha-\beta p_{e}^{D}\right) \\
\text { s.t. } & \max _{p_{r}^{D}} U_{r}^{D}=(1+\lambda)\left(p_{r}^{D}-w^{D}\right)\left(\alpha-\beta p_{r}^{D}\right) \\
& -\lambda\left[w^{D}\left(\alpha-\beta p_{r}^{D}\right)+p_{e}^{D}\left(1-\alpha-\beta p_{e}^{D}\right)\right] .
\end{array}
$$

By using the reverse induction, we have the optimal results for model $D$, which are described in Proposition 1 .

Proposition 1. In model $D$, the optimal prices are given as $w^{D^{*}}=\alpha(1+\lambda) /(2 \beta(1+2 \lambda)), \quad P_{e}^{D^{*}}=(1-\alpha) /(2 \beta) \quad$ and $P_{r}^{D^{*}}=3 \alpha /(4 \beta)$.

The proof is given in Appendix A.

And thus, the optimal demands, profit, and utility are shown as $D_{e}^{D^{*}}=(1-\alpha) / 2, \quad D_{r}^{D^{*}}=\alpha / 4, \quad \pi_{m}^{D^{*}}=\alpha^{2}(1+\lambda) /$ $(8 \beta(1+2 \lambda))+(1-\alpha)^{2} /(4 \beta)$ and $U_{r}^{D^{*}}=\alpha^{2}(1+\lambda) /(16 \beta)-$ $\lambda(1-\alpha)^{2} /(4 \beta)$.

4.2. Retailer Direct Selling Mode (Model R). In model $R$, the retailer's vertical fairness concerns about the manufacturer's profit are considered. The manufacturer firstly determines the wholesale price $w^{R}$ to maximize its profit. And then, the retailer determines the retail prices $p_{r}^{R}$ and $p_{e}^{R}$ of offline and online channels to maximize its utility. The manufacturer and the retailer play a Stackelberg game, and the optimization model is formulated as

$$
\begin{array}{ll}
\max _{w^{R}} & \pi_{m}^{R}=w^{R}\left(1-\beta p_{r}^{R}-\beta p_{e}^{R}\right) \\
\text { s.t. } & \max _{p_{e}^{R}, p_{r}^{R}} U_{r}^{R}=(1+\lambda)\left[\left(p_{r}^{R}-w^{R}\right)\left(\alpha-\beta p_{r}^{R}\right)+\left(p_{e}^{R}-w^{R}\right)\right. \\
& \left.\quad\left(1-\alpha-\beta p_{e}^{R}\right)\right]-\lambda w^{R}\left(1-\beta p_{r}^{R}-\beta p_{e}^{R}\right) .
\end{array}
$$

By using the reverse induction, we have the optimal results for model $R$, which are described in Proposition 2. 
Proposition 2. In model $R$, the optimal prices are given as $w^{R *}=(1+\lambda) /(4 \beta(1+2 \lambda)), \quad p_{e}^{R *}=(5-4 \alpha) /(8 \beta) \quad$ and $p_{r}^{R *}=(1+4 \alpha) /(8 \beta)$.

The proof is given in Appendix B.

And thus, the optimal demands, profit, and utility are $D_{r}^{R *}=(4 \alpha-1) / 8, \quad D_{e}^{R *}=(3-4 \alpha) / 8, \quad \pi_{m}^{R *}=(1+\lambda) /(16 \beta$ $(1+2 \lambda))$ and $U_{r}^{R *}=(1+\lambda)\left(16 \alpha^{2}-16 \alpha+5 s\right) /(32 \beta)$.

4.3. E-Commerce Platform Agency Selling Mode (Model A). In model $A$, the retailer's vertical and horizontal fairness concerns about the manufacturer's and e-commerce platform' profits are considered. The manufacturer firstly determines the wholesale price $w^{A}$ and retail price $p_{e}^{A}$ of e-commerce platform online channel to maximize its profit. And then, the retailer determines the retail price $p_{r}^{A}$ of offline channel to maximize its utility. The commission fee proportion $s$ is assumed to be an exogenous variable [31, 51]. The manufacturer and the retailer play a Stackelberg game, and the optimization model is formulated as

$$
\begin{gathered}
\max _{p_{e}^{A}, w^{A}} \pi_{m}^{A}=w^{A}\left(\alpha-\beta p_{r}^{A}\right)+(1-s) p_{e}^{A}\left(1-\alpha-\beta p_{e}^{A}\right) \\
\text { s.t. } \max _{p_{r}^{A}} U_{r}^{A}=(1+\lambda+\gamma)\left(p_{r}^{A}-w^{A}\right)\left(\alpha-\beta p_{r}^{A}\right) \\
-\lambda \pi_{m}^{A}-\gamma s p_{e}^{A}\left(1-\alpha-\beta p_{e}^{A}\right) .
\end{gathered}
$$

By using the reverse induction, we have the optimal results for model $A$, which are described in Proposition 3.

Proposition 3. In model $A$, the optimal prices are given as $w^{A *}=(1+\lambda+\gamma) \alpha /(2 \beta(1+2 \lambda+\gamma)), \quad p_{e}^{A *}=(1-\alpha) /(2 \beta)$ and $p_{r}^{A *}=3 \alpha /(4 \beta)$.

The proof is given in Appendix C.

And thus, the resulting optimal demands, profit, and utility are shown as $D_{e}^{A^{*}}=1-\alpha / 2, D_{r}^{A^{*}}=\alpha / 4, \pi_{m}^{A *}=(1+$ $\lambda+\gamma) \alpha^{2} / 8 \beta(1+2 \lambda+\gamma)+(1-s)(1-\alpha)^{2} / 4 \beta$ and $U_{r}^{A^{*}}=(1$ $+\lambda+\gamma) \alpha^{2} / 16 \beta-(\lambda-\lambda s+\gamma s)(1-\alpha)^{2} / 4 \beta$.

\section{Sensitive and Comparative Analyses of Equilibrium Results}

5.1. Sensitive Analysis. In the three models $D, R$, and $A$, by analyzing the effect of the retailer's vertical fairness concern coefficients $\lambda$ and $\gamma$ on the optimal decisions in the dualchannel supply chain, the following conclusions can be drawn.

Analyzing the effects of the parameters $\lambda$ and $\gamma$ on the optimal retail prices and wholesale prices in the three models, we have Proposition 4.

Proposition 4. The optimal retail and wholesale prices in the three models satisfy

(1) $\partial p_{e}^{i^{*}} / \partial \lambda=\partial p_{r}^{i^{*}} / \partial \lambda=0$ and $\partial p_{e}^{A^{*}} / \partial \gamma=\partial p_{r}^{A^{*}} / \partial \gamma=0$

(2) $\partial w^{i *} / \partial \lambda<0$ and $\partial w^{A *} / \partial \gamma>0, i \in\{D, R, A\}$

The proof is given in Appendix D.

Proposition 4 shows that, in the three models $D, R$, and $A$, the optimal retail prices of online and offline channels setting by the manufacturer or retailer are not affected by the retailer's vertical and horizontal fairness concerns. With the increase of the retailer's vertical fairness concern coefficient $\lambda$ and the decrease of the retailer's horizontal fairness concern coefficient $\gamma$, the manufacturer will decrease the wholesale price. The manufacturer considers the retailer's fairness concerns when determining the wholesale price. But the retailer's fairness concern behavior will not influence the retail prices.

Analyzing the effects of the parameters $\lambda$ and $\gamma$ on the manufacturer's profits and the retailer's utilities in the three models, we have Proposition 5.

Proposition 5. The optimal profit and utility in the three models satisfy

(1) $\partial \pi_{m}^{i^{*}} / \partial \lambda<0$ and $\partial \pi_{m}^{A^{*}} / \partial \gamma>0$

(2) if $2 / 3<\alpha<1$, then $\partial U_{r}^{D} / \partial \lambda>0$; where $i \in\{D, R, A\}$, $\widehat{S}_{1}=\left(3 \alpha^{2}-8 \alpha+4\right) /\left(4(1-\alpha)^{2}\right)$ and $\widehat{S}_{2}=\alpha^{2} /$ $\left(4(1-\alpha)^{2}\right) \partial U_{r}^{R *} / \partial \lambda>0$; if $2 / 3 \leq \alpha<1$ or $0<\alpha<2 / 3$ and $\widehat{S}_{1}<s<1$, then $\partial U_{r}^{A^{*}} / \partial \lambda>0$; if $0<\alpha<2 / 3$ and $\widehat{S}_{2}<s<1$, then $\partial U_{r}^{A^{*}} / \partial \gamma<0$, where $i \in\{M, R, A\}, \widehat{S}_{1}=$ $3 \alpha^{2}-8 \alpha+4 / 4(1-\alpha)^{2}$ and $\widehat{S}_{2}=\alpha^{2} / 4(1-\alpha)^{2}$

The proof is given in Appendix E.

Proposition 5 (1) shows that, in the three models $D, R$ and $A$, with the increase of the retailer's vertical fairness concern coefficient $\lambda$ and the decrease of the retailer's horizontal fairness concern coefficient $\gamma$, the manufacturer's profit decreases, because the manufacturer decreases the wholesale price by considering the retailer's vertical fairness concern. That is to say, the retailer's vertical fairness concern behavior will damage the manufacturer's profit, but the retailer's horizontal fairness concern behavior is beneficial for the manufacturer.

Proposition 5 (2) indicates that, in model $D$, only when the offline channel demand proportion $\alpha$ is extremely high, the retailer's utility increases with the increase of the retailer's vertical fairness concern coefficient $\lambda$. In model $R$, with the increase of the retailer's vertical fairness concern coefficient $\lambda$, the retailer's utility increases, which does not need any conditions. In model $A$, when the offline channel demand proportion $\alpha$ is extremely high, or when the offline channel demand proportion $\alpha$ is low and the commission fee proportion $s$ is higher than $\widehat{S}_{1}$, the retailer's utility increases with the increase of the retailer's vertical fairness concern coefficient $\lambda$. When the offline channel demand proportion $\alpha$ is low, and the commission fee proportion $s$ is higher than $\widehat{S}_{2}$, with the increase of the retailer's horizontal fairness concern coefficient $\gamma$, the retailer's utility decreases. Under different online channel modes, the retailer's fairness concern behavior is not necessarily conducive to its profit.

5.2. Comparative Analysis. By comparing the equilibrium results in the three models $D, R$, and $A$, the following conclusions can be drawn.

Comparing the optimal wholesale prices and retail prices in the three models, we have Proposition 6. 
Proposition 6. The optimal wholesale prices and retail prices in the three models satisfy

(1) if $0<\alpha<1 / 2$, then $w^{R *}>w^{A *}>w^{D^{*}}$; otherwise, $w^{A *}>w^{D^{*}}>w^{R *}$

(2) $p_{e}^{R *}>p_{e}^{A *}=p_{e}^{D^{*}}$; if $0<\alpha<1 / 2$, then $p_{r}^{R *}>$ $p_{r}^{A *}=p_{r}^{D^{*}} ;$ otherwise, $p_{r}^{A *}=p_{r}^{D^{*}}>p_{r}^{R *}$

The proof is given in Appendix F.

Proposition 6 (1) indicates that when the offline channel demand proportion $\alpha$ is less than 0.5 , the manufacturer will set the highest wholesale price under retailer direct selling mode, but it will set the lowest wholesale price under manufacturer direct selling mode. While when the offline channel demand proportion $\alpha$ is higher than 0.5 , the manufacturer will set the highest wholesale price under e-commerce platform agency selling mode, but it will set the lowest wholesale price under remanufacturer direct selling mode.

Propositions 6 (2) shows that no matter what the conditions are, the retail price of online channel in model $R$ is the highest. When the offline channel demand proportion $\alpha$ is less than 0.5 , the retail price in model $R$ is the highest. While when the offline channel demand proportion $\alpha$ is higher than 0.5 , the retail price in model $R$ is the lowest. The retail prices of online and offline channels in the models $A$ and $D$ are the same. That is to say, the retailer's fairness concerns and channel mode do not affect the manufacturer's decision on the retail price of online channel and the retailer's decision on the retail price of offline channel.

In order to analyze the effect of the retailer's fairness concerns on the online channel mode strategy, we firstly analyze the relationship of the manufacturer's profit and the retailer's utility in the three models without the retailer's fairness concerns. Setting $\lambda=0$ and $\gamma=0$, and comparing the manufacturer's optimal profit and the retailer's optimal utility in the three models ND, NR and NA, we have Proposition 7.

Proposition 7. Without the retailer's fairness concerns, the optimal profits and utilities in the three models satisfy

(1) if $0<\alpha<\sqrt{2} / 2$ and $\widehat{S}_{3}<s<1$, then $\pi_{m}^{N D^{*}}>\pi_{m}^{N R}$ $*>\pi_{m}^{N A *}$; otherwise, $\pi_{m}^{N D^{*}}>\pi_{m}^{N A *}>\pi_{m}^{N R *}$, where $\widehat{S}_{3}=\left(6 \alpha^{2}-8 \alpha+3\right) /\left(4(1-\alpha)^{2}\right)$

(2) $U_{r}^{N R^{*}}>U_{r}^{N D^{*}}=U_{r}^{N A^{*}}$

The proof is given in Appendix G.

Proposition 7 shows that when the offline channel demand proportion $\alpha$ is less than $\sqrt{2} / 2$ and the commission fee proportion $s$ is higher than $\widehat{S}_{3}$, the manufacturer's profit in the model NR is higher than that in model NA. On the contrary, the manufacturer's profit in the model NA is higher than that in model NR. But the manufacturer's profit in model ND is the highest, and thus, the manufacturer direct selling mode is the best online channel mode strategy for the manufacturer without the retailer's fairness concerns, while the retailer's utilities in the models ND and NA are the same, and its utility in model NR is the highest. The retailer direct selling mode is the most beneficial for the retailer without the retailer's fairness concerns. The manufacturer direct selling mode chosen by the manufacturer will damage the retailer's utility. Without the retailer's fairness concerns, the manufacturer will choose the manufacturer direct selling mode, but the interests of the manufacturer and retailer are inconsistent.

Comparing the manufacturer's optimal profit and the retailer's optimal utility in the three models $D, R$ and $A$, we have Proposition 8.

Proposition 8. With the retailer's fairness concerns, the optimal profits and utilities in the three models satisfy

(1) if $0<s<\min \left\{\widehat{S}_{4}, \widehat{S}_{5}\right\}$, then $\pi_{m}^{A *}>\pi_{m}^{D^{*}}>\pi_{m}^{R *}$; if $\max \left\{\widehat{S}_{4}, \widehat{S}_{5}\right\}<s<1$, then $\pi_{m}^{D^{*}}>\pi_{m}^{R *}>\pi_{m}^{A *}$

(2) if $0<s<\widehat{S}_{6}$, then $U_{r}^{R^{*}}>U_{r}^{A *}>U_{r}^{D^{*}}$; otherwise, $U_{r}^{A^{*}}>U_{r}^{R *}>U_{r}^{D^{*}}$, where $\widehat{S}_{4}=\lambda \gamma \alpha^{2} /(2(1+2 \lambda) \quad(1+$ $\left.2 \lambda+\gamma)(1-\alpha)^{2}\right), \widehat{S}_{5}=[(1+2 \lambda)[8(1+\gamma) \alpha-2(1-\lambda+$ $\left.\left.\gamma) \alpha^{2}-5(1+\gamma)\right]-\gamma(1+\lambda)\right] /(4(1+2 \lambda)(1+2 \lambda+\gamma)$ $\left.(1-\alpha)^{2}\right)$ and $\hat{S}_{6}=\left[(1+\lambda)\left(14 \alpha^{2}-16 \alpha+5\right)+8 \lambda\right.$ $\left.(1-\alpha)^{2}-2 \gamma \alpha^{2}\right] /\left(8(\lambda-\gamma)(1-\alpha)^{2}\right)$

The proof is given in Appendix $\mathrm{H}$.

From Proposition 8 we can find that when the commission fee proportion $s$ is extremely small, the manufacturer's profit in model $A$ is the highest, and its profit in model $R$ is the lowest. Thus, the manufacturer will choose the e-commerce platform agency selling mode with the retailer's fairness concerns, while when the commission fee proportion $s$ is extremely high, the manufacturer's profit in model $D$ is the highest, and its profit in model $A$ is the lowest. And thus, the manufacturer will choose the manufacturer direct selling mode with the retailer's fairness concerns. The manufacturer will not adopt the retailer direct selling mode. But when the commission fee proportion $s$ is less than $\widehat{S}_{6}$, the retailer's utility in the model $R$ is the highest, and its utility in the model $D$ is the lowest. On the contrary, the retailer's utility in the model $A$ is the highest, and its utility in the model $D$ is the lowest. The retailer does not want the manufacturer to choose the manufacturer direct selling mode. With the retailer's fairness concerns, in some cases, the interests of the manufacturer and retailer are inconsistent.

Propositions 7 and 8 indicate that, without the retailer's fairness concerns, the manufacturer will choose the manufacturer direct selling mode, which will damage the retailer's benefit, while, with the retailer's vertical and horizontal fairness concerns, the manufacturer's decision of online channel mode strategy depends on the parameter of the commission fee proportion $s$. When the commission fee proportion $s$ is extremely small, the manufacturer will choose the e-commerce platform agency selling mode. Otherwise, the manufacturer will choose the manufacturer direct selling mode. With the retailer's fairness concerns, when the commission fee proportion $s$ meets a certain range, the e-commerce platform agency selling mode is the best choice for the manufacturer and retailer. The retailer's fairness concerns behavior changes the optimal online channel mode strategy. 


\section{Numerical Analysis}

To illustrate the impacts of the retailer's fairness concerns on the decisions of the dual-channel supply chain members and the online channel mode strategy, a numerical experimental design is used in this section. Following Pan et al. [15], Pu et al. [31], and Wuttke et al. [49], the parameters are set as $\alpha=0.7, \beta=0.2$.

By setting $s=0.1, \lambda$ and $\gamma$ vary within the range of $[0,1]$, the impacts of the retailer's vertical fairness concern coefficient $\lambda$ and horizontal fairness concern coefficient $\gamma$ on the manufacturer's profit and the retailer's utility are firstly analyzed, which are described in Figures 2 and 3.

Figure 2 indicates that, with the increase of the retailer's vertical fairness concern coefficient $\lambda$ and the decrease of the retailer's horizontal fairness coefficient $\gamma$, the manufacturer's profits in the three models all decrease, which verifies the conclusions in Proposition 5. The manufacturer chooses the online channel mode between the manufacturer direct selling and the e-commerce platform agency selling modes. When the retailer's horizontal fairness concern coefficient or the retailer's vertical fairness concern coefficient is small, the manufacturer will choose the manufacturer direct selling mode; otherwise, it will choose the e-commerce platform agency selling mode, which verifies the conclusions in Proposition 8.

Figure 3 shows that, with the increase of the retailer's vertical fairness concern coefficient $\lambda$, the retailer's utilities in the models $D$ and $R$ increase. Since $\alpha=0.7>2 / 3$, with the increase of the retailer's vertical and horizontal fairness concern coefficients $\lambda$ and $\gamma$, the retailer's utility in the model $A$ increases. These verify the conclusions in Proposition 5. In most cases, the retailer direct selling mode is beneficial for the retailer. The manufacturer's optimal online channel mode is not conducive to the retailer under most conditions.

From Figures 2 and 3 we can also find that, without the retailer's fairness concerns, i.e., $\lambda=\gamma=0$, the manufacturer direct selling mode is most beneficial for the manufacturer, while the retailer direct selling mode is most beneficial for the retailer, which verifies the conclusions in Proposition 7, while, with the retailer's fairness concerns, when the retailer's fairness concern coefficients meet a certain range, the e-commerce platform agency selling is the best choice for the manufacturer and the retailer. The retailer's fairness concerns change the optimal online channel mode strategy, which verifies the conclusions in Proposition 8.

By setting $\lambda=0.2, \gamma=0.2$, and $s$ varies within the range of $[0,1]$, the impacts of the commission fee proportion $s$ on the manufacturer's profit are analyzed, which are described in Figure 4.

Figure 4 indicates that, with the increase of the commission fee proportion $s$, the manufacturer's profit in model $A$ decreases. The manufacturer decision of the optimal online channel mode depends the commission fee proportion. When the commission fee proportion is extremely small, the manufacturer's profit in model $A$ is the highest; thus, the manufacturer will choose the e-commerce platform agency selling mode. On the contrary, when the commission fee proportion is high, the manufacturer's profit in the

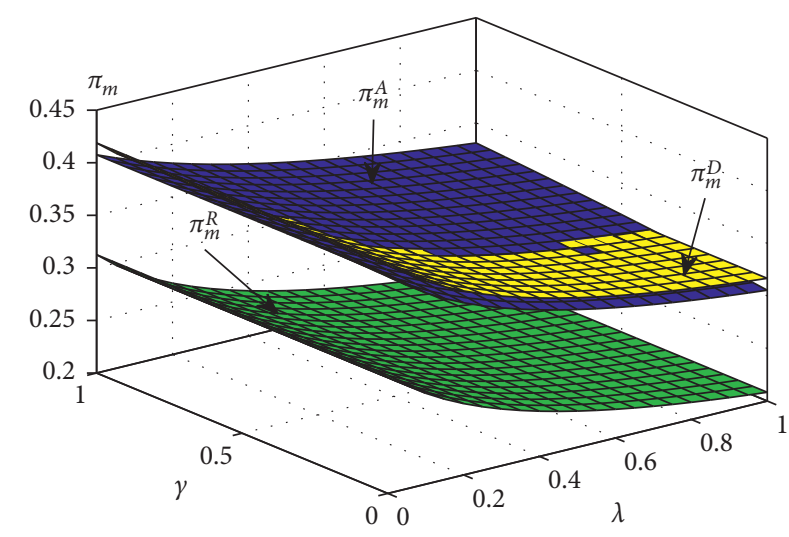

FIGURE 2: Impact of the retailer's fairness concerns on the manufacturer's profit.

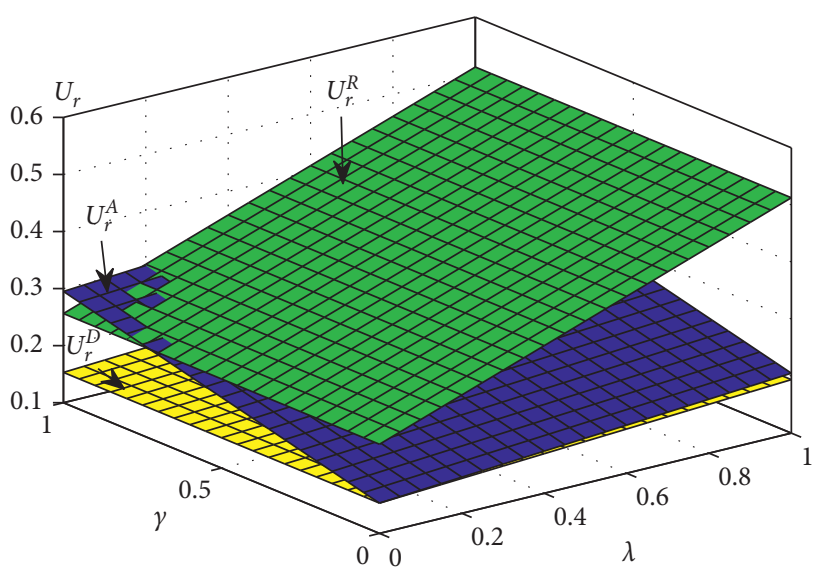

FIGURE 3: Impact of the retailer's fairness concerns on the retailer's utility.

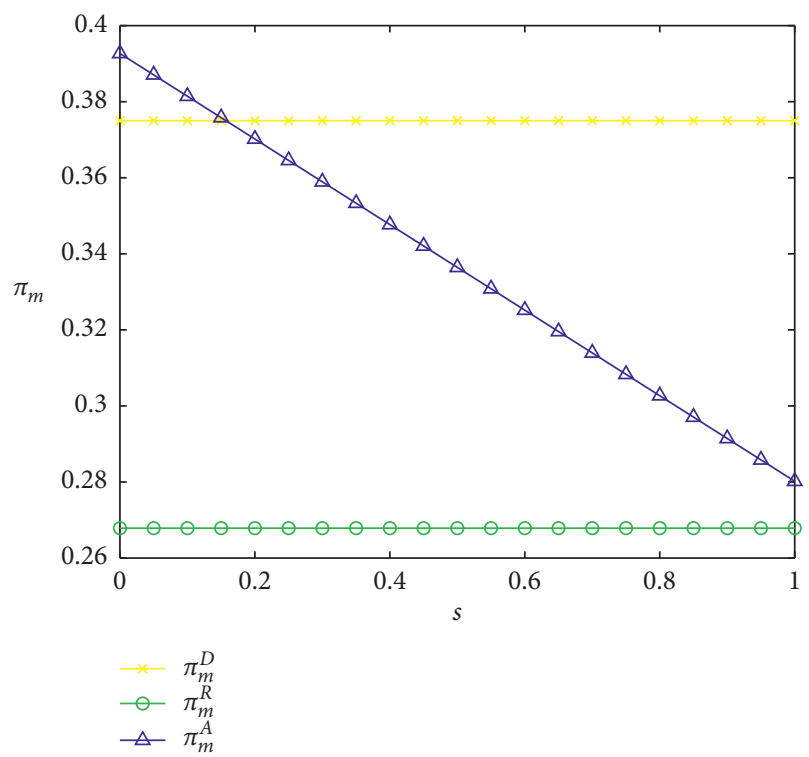

FIGURE 4: Impact of the commission fee on the manufacturer's profit. 
model $D$ is the highest; thus, the manufacturer direct selling mode is the best choice for the manufacturer, which verifies the conclusions in Proposition 8.

In order to describe the different relationships of the retailer's utility in the three models, by setting $\lambda=0.2$, and $\gamma$ and $s$ vary within the range of $[0,1]$, the impacts of the retailer's horizontal fairness concern coefficient and the commission fee proportion on the retailer's utility are analyzed, which are shown in Figure 5.

Figure 5 shows that, with the increase of the commission fee proportion $s$, the retailer's utility in model $A$ increases. The retailer's horizontal fairness concerns increase its utility. Under most conditions, the retailer's utility in the model $R$ is the highest; thus, the retailer is more inclined to the retailer direct selling mode strategy, which is contrary to the manufacturer's choice. But when the commission fee proportion is extremely small and the retailer's horizontal fairness concern coefficient is extremely high, the e-commerce platform agency selling mode is the most beneficial for the retailer. That is to say, when the parameters meet some conditions, the e-commerce platform agency selling mode strategy is the best choice for the manufacturer and the retailer. These verify the conclusions in Proposition 8.

From Figures 2-5, we can find that, without the retailer's fairness concerns, the manufacturer direct selling mode strategy is the best for the manufacturer, while the retailer direct selling mode strategy is the most benefit for the retailer. With the retailer's fairness concerns, the manufacturer chooses the optimal online channel mode strategy between the manufacturer direct selling and the e-commerce platform agency selling modes. These two online channel mode strategies all harm the retailer's benefit. Under most conditions, the benefits of the manufacturer and the retailer are conflicting. Only the retailer's fairness concern coefficients and commission fee proportion satisfy some conditions, and the e-commerce platform agency selling mode strategy is the consistent choice for the manufacturer and the retailer.

\section{Discussions and Conclusions}

7.1. Discussions. In this paper, we show that the retailer's vertical and horizontal fairness concerns play a key role in the operation of dual-channel supply chain. Especially, the fairness concern behavior has a significant impact on the decisionmaking of supply chain members and the online channel mode strategy. Although there are important discoveries revealed by these studies, there are also limitations. First, limited research has considered the impact of fairness concerns on channel mode strategy. Second, there are few literatures that consider both vertical and horizontal fairness concerns in a dual-channel supply chain. Last, limited attention is dedicated to the online channel mode strategy, especially the channel model strategy selection among the traditional dual-channel mode (the manufacturer direct selling mode), $\mathrm{O} 2 \mathrm{O}$ mode integrated of online and offline channels (the retailer direct selling mode), and e-commerce platform agency selling mode.

Our studies establish three dynamic Stackelberg game models to analyze the impact of the retailer's vertical and horizontal fairness concerns on the online channel mode

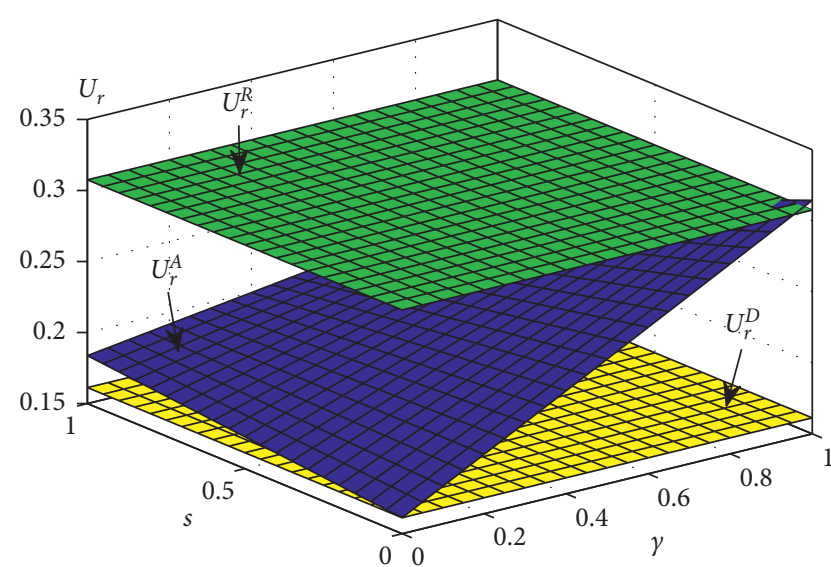

FIgURE 5: Impact of the commission fee and retailer's fairness concerns on the retailer's utility.

strategy. We have identified that the retailer's fairness concerns change the optimal online channel mode strategy and shown that, under some conditions, the e-commerce platform agency selling mode is the best for the supply chain members. Our results suggest a possibility of an optimal online channel mode strategy, which can solve the conflict among supply chain members. In summary, we have given an effective method of selecting the online channel structure mode strategy by simultaneously considering the retailer's vertical and horizontal fairness concerns.

7.2. Conclusions. Based on a dual-channel supply chain consisting of a manufacturer and a retailer, this paper takes the retailer's vertical and horizontal fairness concerns into account under three online channel mode strategies: the manufacturer direct selling mode (model $D$ ), the retailer direct selling mode (model $R$ ), and the e-commerce platform agency selling mode (model $A$ ). The impact of the retailer's fairness concerns on the decisions and performance of the dual-channel supply chain is analyzed, and the optimal online channel mode strategy is given.

The results show that (1) the retailer's fairness concern behavior does not affect the retail prices of online and offline channel products but affects the wholesale price and online channel mode strategy. (2) The retailer's vertical fairness concern is disadvantageous for the manufacturer, but the retailer's horizontal fairness concern is beneficial for the manufacturer. The retailer's fairness concerns do not necessarily improve the retailer's utility. (3) Without the retailer's fairness concerns, the manufacturer direct selling mode strategy is the best for the manufacturer, which harms the retailer's utility. With the retailer's fairness concerns, the manufacturer direct selling and e-commerce platform agency selling modes are better for the manufacturer. But the retailer direct selling and e-commerce platform agency selling modes are better for the retailer. (4) When the parameters meet a certain range, the e-commerce platform agency selling mode is the best online channel mode strategy, and the interests of the dual-channel supply chain members are consistent. 
There are still some problems not considered in this paper. Firstly, we only considered the retailer's fairness concerns and did not consider the manufacturer's fairness concern behavior. In reality, the two supply chain members' fairness concerns may coexist. It would be interesting to incorporate other supply chain member's fairness concern behaviors and examine their impacts on the supply chain decisions and online channel mode strategy. Secondly, this paper only investigates the game between the manufacturer and retailer. It is well known that the e-commerce platform plays an important role in the dual-channel supply chain. It is worthwhile to extend this research to a more complex game among a manufacturer, a retailer, and an e-commerce platform. Thirdly, we consider three online channel mode strategies in this study. There exist many channel mode strategies in practice, such as e-retailer online direct selling mode and manufacturer dual-channel mode. Different channel modes will be considered in a dual-channel supply chain in the future research.

\section{Appendix}

\section{A. Proof of Proposition 1}

In model $D$, since $\partial^{2} U_{r}^{D} / \partial p_{r}^{D 2}=-2 \beta(1+\lambda)<0, U_{r}^{D}$ is strictly concave on $p_{r}^{D}$. It can be obtained from $\partial U_{r}^{D} / \partial p_{r}^{D}=0$ that $\quad p_{r}^{D}=\left(\alpha(1+\lambda)+\beta(1+2 \lambda) w^{D}\right) /(2 \beta(1+\lambda))$. By substituting $p_{r}^{D}$ into $\pi_{m}^{D}$, the Hessian matrix of $\pi_{m}^{D}$ in terms of $w^{D}$ and $p_{e}^{D}$ is $H^{D}=[-\beta(1+2 \lambda) /(1+\lambda) \quad 00-2 \beta]$. From the assumption $0<\beta<1$ and $0<\lambda<1$, it can be shown that $\left|H_{1}^{D}\right|=-\beta(1+2 \lambda) /(1+\lambda)<0$ and $\left|H_{2}^{D}\right|=2 \beta^{2}(1+2 \lambda) /$ $(1+\lambda)>0$. Therefore, $H^{D}$ is negative definite, and $\pi_{m}^{D}$ is strictly concave with respect to $w^{D}$ and $p_{e}^{D}$. It can be obtained from $\partial \pi_{m}^{D} / \partial w^{D}=0$ and $\partial \pi_{m}^{D} / \partial p_{e}^{D}=0$ that $w^{D^{*}}=\alpha(1+\lambda) /(2 \beta(1+2 \lambda)) \quad$ and $p_{e}^{D^{*}}=(1-\alpha) /(2 \beta)$. Substituting $w^{D^{*}}$ into $p_{r}^{D}$, we have $p_{r}^{D^{*}}=3 \alpha / 4 \beta$.

\section{B. Proof of Proposition 2}

In model $R$, the Hessian matrix of $U_{r}^{R}$ in terms of $p_{e}^{R}$ and $p_{r}^{R}$ is $H^{R}=\left[\begin{array}{cc}-2 \beta(1+\lambda) & 0 \\ 0 & -2 \beta(1+\lambda)\end{array}\right]$. From the assumption $0<\beta<1$ and $0<\lambda<1$, it can be shown that $\left|H_{1}^{R}\right|=-2 \beta(1+$ $\lambda)<0$ and $\left|H_{2}^{R}\right|=4 \beta^{2}(1+\lambda)^{2}>0$. Therefore, $H^{R}$ is negative definite, and $U_{r}^{R}$ is strictly concave with respect to $p_{e}^{R}$ and $p_{r}^{R}$. It can be obtained from $\partial U_{r}^{R} / \partial p_{r}^{R}=0$ and $\partial U_{r}^{R} / \partial p_{e}^{R}=0$ that $p_{r}^{R}=\left((1+\lambda) \alpha+(1+2 \lambda) \beta w^{R}\right) /(2 \beta(1+\lambda))$ and $p_{e}^{R}=(1+$ $\lambda)(1-\alpha)+(1+2 \lambda) \beta w^{R} / 2 \beta(1+\lambda)$. Substituting $p_{e}^{R}$ and $p_{r}^{R}$ into $\pi_{m}^{R}$, since $\partial^{2} \pi_{m}^{R} / \partial w^{R 2}=-(1+2 \lambda) \beta /(1+\lambda)<0, \pi_{m}^{R}$ is strictly concave on $w^{R}$. It can be obtained from $\partial \pi_{m}^{R} / \partial w^{R}=0$ that $w^{R *}=(1+\lambda) /(4 \beta(1+2 \lambda))$.

\section{Proof of Proposition 3}

In model $A$, since $\partial^{2} U_{r}^{A} / \partial p_{r}^{A 2}=-2 \beta(1+\lambda+\gamma)<0, U_{r}^{R}$ is strictly concave on $p_{r}^{R}$. It can be obtained from $\partial U_{r}^{A} / \partial p_{r}^{A}=0$ that $p_{r}^{A}=\left((1+\lambda+\gamma) \alpha+\beta(1+2 \lambda+\gamma) w^{A}\right) /(2 \beta(1+\lambda+\gamma))$. By substituting $p_{r}^{A}$ into $\pi_{m}^{A}$, the Hessian matrix of $\pi_{m}^{A}$ in terms of $w^{A}$ and $p_{e}^{A}$ is $H^{A}=[-\beta(1+2 \lambda+\gamma) /(1+\lambda+\gamma) \quad 0$ $0-2 \beta(1-s)$ ]. From the assumption $0<\beta<1,0<\lambda<1$ and $0<\gamma<1$, it can be shown that $\left|H_{1}^{A}\right|=-\beta(1+2 \lambda+\gamma) /$ $(1+\lambda+\gamma)<0$ and $\left|H_{2}^{A}\right|=2 \beta^{2}(1+2 \lambda+\gamma)(1-s) /(1+\lambda$ $+\gamma)>0$. Therefore, $H^{R}$ is negative definite, and $\pi_{m}^{A}$ is strictly concave with respect to $w^{A}$ and $p_{e}^{A}$. It can be obtained from $\partial \pi_{m}^{A} / \partial w^{A}=0$ and $\partial \pi_{m}^{A} / \partial p_{e}^{A}=0$ that $w^{A *}=(1+\lambda+\gamma) \alpha /(2 \beta$ $(1+2 \lambda+\gamma))$ and $p_{e}^{A *}=1-\alpha / 2 \beta$. Substituting $w^{A *}$ and $p_{e}^{A *}$ into $p_{r}^{A}$, we have $p_{r}^{A *}=3 \alpha / 4 \beta$.

\section{Proof of Proposition 4}

Since $0<\alpha<1,0<\beta<1,0<\lambda<1$ and $0<\gamma<1$, it can be easily verified that

(1) $\partial p_{e}^{D^{*}} / \partial \lambda=\partial p_{r}^{D^{*}} / \partial \lambda=\partial p_{e}^{R^{*}} / \partial \lambda=\partial p_{r}^{R^{*}} / \partial \lambda=\partial p_{e}^{A^{*}} /$ $\partial \lambda=\partial p_{r}^{A^{*}} / \partial \lambda=0$ and $\partial p_{e}^{A^{*}} / \partial \gamma=\partial p_{r}^{A^{*}} / \partial \gamma=0$

(2) $\partial w^{D^{*}} / \partial \lambda=-\alpha /\left(2 \beta(1+2 \lambda)^{2}\right)<0, \partial w^{R *} / \partial \lambda=-1 /(4 \beta$ $\left.(1+2 \lambda)^{2}\right)<0, \quad \partial w^{A *} / \partial \lambda=-(1+\gamma) \alpha /(2 \beta(1+2 \lambda$ $\left.+\gamma)^{2}\right)<0$, and $\partial w^{A *} / \partial \gamma=\lambda \alpha /\left(2 \beta(1+2 \lambda+\gamma)^{2}\right)>0$

\section{E. Proof of Proposition 5}

Since $0<\alpha<1,0<\beta<1,0<\lambda<1$ and $0<\gamma<1$, it can be easily verified that

(1) $\partial \pi_{m}^{D^{*}} / \partial \lambda=-\alpha^{2} /\left(8 \beta(1+2 \lambda)^{2}\right)<0, \quad \partial \pi_{m}^{R *} / \partial \lambda=-1 /$ $\left(16 \beta(1+2 \lambda)^{2}\right)<0, \partial \pi_{m}^{A *} / \partial \lambda=-(1+\gamma) \alpha^{2} /(8 \beta(1+$ $\left.2 \lambda+\gamma)^{2}\right)<0$, and $\partial \pi_{m}^{A *} / \partial \gamma=\lambda \alpha^{2} /\left(8 \beta(1+2 \lambda+\gamma)^{2}\right)$ $>0$.

(2) $\partial U_{r}^{D^{*}} / \partial \lambda=(-3 \alpha+2)(\alpha-2) /(16 \beta)$, thus, if $2 / 3<$ $\alpha<1$, then $\partial U_{r}^{D^{*}} / \partial \lambda>0 ; \partial U_{r}^{R *} / \partial \lambda=\left(16 \alpha^{2}-16 \alpha+\right.$ $5) /(32 \beta)>0 ; \quad \partial U_{r}^{A^{*}} / \partial \lambda=\left(-3 \alpha^{2}+8 \alpha-4+4 s \quad(1-\right.$ $\left.\alpha)^{2}\right) /(16 \beta)$, if $2 / 3 \leq \alpha<1$, then $-3 \alpha^{2}+8 \alpha-4 \geq 0$, thus, $\quad \partial U_{r}^{A^{*}} / \quad \partial \lambda>0, \quad$ if $0<\alpha<2 / 3$, then $-3 \alpha^{2}+8 \alpha-4<0$, only when $\left(3 \alpha^{2}-8 \alpha+4\right) /$ $\left(4(1-\alpha)^{2}\right)<s<1, \partial U_{r}^{A^{*}} / \partial \lambda>0$. Similarly, we can verify that if $0<\alpha<2 / 3$ and $\alpha^{2} /\left(4(1-\alpha)^{2}\right)<s<1$, then $\partial U_{r}^{A^{*}} / \partial \gamma=\left(\alpha^{2}-4 s(1-\alpha)^{2}\right) /(16 \beta)<0$.

\section{F. Proof of Proposition 6}

(1) Comparing the optimal wholesale prices in the three models $D, R$ and $A$, we have $w^{A *}-w^{D^{*}}=\lambda \gamma \alpha /$ $(2 \beta(1+2 \lambda)(1+2 \lambda+\gamma))>0, \quad$ if $1 / 2<\alpha<1$, then $w^{R *}-w^{D^{*}}=(1+\lambda)(1-2 \alpha) /(4 \beta(1+2 \lambda))<0$, if 0 $<\alpha<1 / 2$, then $w^{A *}-w^{R *}=\left[(2 \alpha-1)\left(1+\gamma+2 \lambda^{2}\right.\right.$ )$+2 \lambda(\alpha-1)+\lambda(4 \alpha-1)(1+\gamma)] /(4 \beta(1+2 \lambda)(1+2$ $\lambda+\gamma))<0$. Thus, if $0<\alpha<1 / 2$, then $w^{R *}>w^{A *}$ $>w^{D^{*}}$, and if $1 / 2<\alpha<1$, then $w^{A *}>w^{D^{*}}>w^{R *}$.

(2) Comparing the optimal retail prices in the three models $D, R$, and $A$, we have $p_{e}^{A *}=p_{e}^{D^{*}}=(1-$ $\alpha) /(2 \beta)$ and $p_{e}^{R *}-p_{e}^{D^{*}}=1 / 8 \beta>0$, thus $p_{e}^{R *}>p_{e}^{A *}=p_{e}^{D^{*}}$. We can also obtain $p_{r}^{A *}=p_{r}^{D^{*}}=$ $3 \alpha / 4 \beta$ and $p_{r}^{R *}-p_{r}^{D^{*}}=(1-2 \alpha) /(8 \beta)$, thus, if $0<\alpha<1 / 2$, then $p_{r}^{R *}-p_{r}^{D^{*}}>0$, otherwise, $p_{r}^{R *}-p_{r}^{D^{*}}<0$. Hence, if $0<\alpha<1 / 2$, then 


$$
\begin{aligned}
& p_{r}^{R *}>p_{r}^{A *}=p_{r}^{D^{*}}, \quad \text { and } \quad \text { if } \quad 1 / 2<\alpha<1, \quad \text { then } \\
& p_{r}^{A *}=p_{r}^{D^{*}}>p_{r}^{R *} .
\end{aligned}
$$

\section{G. Proof of Proposition 7}

Setting $\lambda=0$ and $\gamma=0$, we have $\pi_{m}^{\mathrm{ND}^{*}}=\alpha^{2} / 8 \beta+(1-\alpha)^{2} / 4 \beta$, $\pi_{m}^{\mathrm{NR} *}=1 / 16 \beta, \pi_{m}^{\mathrm{NA} *}=\alpha^{2} / 8 \beta+(1-s)(1-\alpha)^{2} / 4 \beta, U_{r}^{\mathrm{ND}^{*}}=$ $\alpha^{2} / 16 \beta, U_{r}^{\mathrm{NR}^{*}}=16 \alpha^{2}-16 \alpha+5 / 32 \beta$ and $U_{r}^{\mathrm{NA}^{*}}=\alpha^{2} / 16 \beta$.

(1) Comparing the manufacturer's profits in the three models $D, R$ and $A$ without retailer's fairness concerns, we have $\pi_{m}^{\mathrm{NR} *}-\pi_{m}^{\mathrm{ND}^{*}}=\left(-6 \alpha^{2}+8 \alpha-\right.$ $3) /(16 \beta)$, denoting $f(\alpha)=-6 \alpha^{2}+8 \alpha-3$, since $\partial^{2} f(\alpha) / \partial \alpha^{2}=-12<0$, setting $\partial f(\alpha) / \partial \alpha=0$ gives $\alpha^{*}=2 / 3$, due to $f\left(\alpha^{*}=2 / 3\right)=-1 / 3<0$, then $f(\alpha)<0$. Thus, $\pi_{m}^{\mathrm{NR} *}-\pi_{m}^{\mathrm{ND}^{*}}<0$. Since $0<\alpha<1$, $0<\beta<1$ and $0<s<1$, it can be easily verified that $\pi_{m}^{\mathrm{NA} *}-\pi_{m}^{\mathrm{ND}^{*}}=-s(1-\alpha)^{2} / 4 \beta<0 . \quad \pi_{m}^{\mathrm{NR} *}-\pi_{m}^{\mathrm{NA} *}=$ $\left(4(1-\alpha)^{2} s-\left(6 \alpha^{2}-8 \alpha+3\right)\right) /(16 \beta)$, it can be verified that if $0<\alpha<\sqrt{2} / 2$ and $6 \alpha^{2}-8 \alpha+3 / 4$ (1$\alpha)^{2}<s<1$, then $\pi_{m}^{\mathrm{NR} *}-\pi_{m}^{\mathrm{NA} *}>0$, if $0<\alpha<\sqrt{2} / 2$ and $0<s<\left(6 \alpha^{2}-8 \alpha+3\right) /\left(4(1-\alpha)^{2}\right)$ or $\sqrt{2} / 2<\alpha<1$, then $\pi_{m}^{\mathrm{NR} *}-\pi_{m}^{\mathrm{NA} *}<0$. Therefore, if $0<\alpha<\sqrt{2} / 2$ and $\left(6 \alpha^{2}-8 \alpha+3\right) /\left(4(1-\alpha)^{2}\right)<s<1$, then $\pi_{m}^{\mathrm{ND}^{*}}>\pi_{m}^{\mathrm{NR}^{*}}$ $>\pi_{m}^{\mathrm{NA}^{*}}$, if $0<\alpha<\sqrt{2} / 2$ and $0<s<\left(6 \alpha^{2}-8 \alpha+3\right) /(4$ $\left.(1-\alpha)^{2}\right)$ or $\sqrt{2} / 2<\alpha<1$, then $\pi_{m}^{\mathrm{ND}^{*}}>\pi_{m}^{\mathrm{NA}^{*}}>\pi_{m}^{\mathrm{NR}^{*}}$.

(2) Comparing the retailer's utilities in the three models $D, R$ and $A$ without retailer's fairness concerns, we have $U_{r}^{\mathrm{ND}^{*}}=U_{r}^{\mathrm{NA}^{*}}=\alpha^{2} / 16 \beta$. Since $0<\alpha<1$, it can be easily verified that $U_{r}^{\mathrm{NR}^{*}}-U_{r}^{\mathrm{ND}^{*}}=\left(14 \alpha^{2}-16 \alpha+\right.$ 5)/(32 $\beta)>0$, thus, $U_{r}^{\mathrm{NR}^{*}}>U_{r}^{\mathrm{ND}^{*}}=U_{r}^{\mathrm{NA}^{*}}$.

\section{H. Proof of Proposition 8}

(1) Comparing the manufacturer's profits in the three models $D, R$, and $A$, we have $\pi_{m}^{R *}-\pi_{m}^{D^{*}}=\left[\left(-10 \alpha^{2}+\right.\right.$ $\left.16 \alpha-7) \lambda-6 \alpha^{2}+8 \alpha-3\right] /(16 \beta(1+2 \lambda))$. It can be easily verified that $-6 \alpha^{2}+8 \alpha-3<0$ and $-10 \alpha^{2}+$ $16 \alpha-7<0$, thus, $\pi_{m}^{R *}-\pi_{m}^{D^{*}}<0$. Similarly, it can be verified that if $0<s<\lambda \gamma \alpha^{2} /(2(1+2 \lambda) \quad(1+2 \lambda$ $\left.+\gamma)(1-\alpha)^{2}\right)$, then $\pi_{m}^{A *}-\pi_{m}^{D^{*}}=\lambda \gamma \alpha^{2} /(8 \beta(1+2 \lambda)$ $(1+2 \lambda+\gamma))-s(1-\alpha)^{2} /(4 \beta)>0$, if $\lambda \gamma \alpha^{2} /(2 \quad(1+$ $\left.2 \lambda)(1+2 \lambda+\gamma)(1-\alpha)^{2}\right)<s<1$, then $\pi_{m}^{A *}-\pi_{m}^{D^{*}}<0$. If $\left[(1+2 \lambda)\left[8(1+\gamma) \alpha-2(1-\lambda+\gamma) \alpha^{2}-5(1+\gamma)\right]-\right.$ $\gamma(1+\gamma)] /\left(4(1+2 \lambda)(1+2 \lambda+\gamma)(1-\alpha)^{2}\right) \quad<s<1$, then $\pi_{m}^{R *}-\pi_{m}^{A *}=\gamma(1+\lambda)+(1+2 \lambda) \quad[2(1-\lambda+$ $\left.\gamma) \alpha^{2}-8(1+\lambda) \alpha+5(1+\lambda)\right] / 16 \beta(1+2 \lambda) \quad(1+2 \lambda+$ $\gamma)+(1-\alpha)^{2} s / 4 \beta>0$, otherwise, $\pi_{m}^{R *}-\pi_{m}^{A *}<0$. Therefore, if $\max \left\{\lambda \gamma \alpha^{2} /(2(1+2 \lambda) \quad(1+2 \lambda+\gamma)\right.$ $\left.(1-\alpha)^{2}\right),\left[(1+2 \lambda)\left[8(1+\gamma) \alpha-2(1-\lambda+\gamma) \alpha^{2}-5\right.\right.$ $(1+\gamma)]-\gamma(1+\lambda)] /(4(1+2 \lambda)(1+2 \lambda+\gamma)(1-$ $\left.\left.\alpha)^{2}\right)\right\}<s<1$, then $\pi_{m}^{D^{*}}>\pi_{m}^{R *}>\pi_{m}^{A *}$, and if $0<s<\min \left\{\lambda \gamma \alpha^{2} /\left(2(1+2 \lambda)(1+2 \lambda+\gamma)(1-\alpha)^{2}\right)\right.$, $\left[(1+2 \lambda) \quad\left[8(1+\gamma) \alpha-2(1-\lambda+\gamma) \alpha^{2}-5(1+\gamma)\right]-\right.$ $\left.\gamma(1+\gamma)] /\left(4(1+2 \lambda)(1+2 \lambda+\gamma)(1-\alpha)^{2}\right)\right\}$, then $\pi_{m}^{A *}>\pi_{m}^{D^{*}}>\pi_{m}^{R *}$.

(2) Comparing the retailer's utilities in the three models $D, \quad R$, and $A$, we have $U_{r}^{A^{*}}-U_{r}^{D^{*}}=\gamma \alpha^{2} /$ $(16 \beta)+(\lambda-\gamma) s(1-\alpha)^{2} / 4 \beta>0 . U_{r}^{D^{*}}-U_{r}^{R *}=((1+$ d) $\left.\left(-14 \alpha^{2}+16 \alpha-5\right)-8 \lambda(1-\alpha)^{2}\right) /(32 \beta)$, since $0<\alpha<1$, it can be verified that $-14 \alpha^{2}+16 \alpha-5<0$,

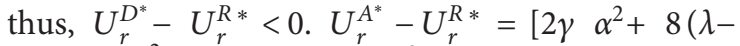
$\gamma) s(1-\alpha)^{2}-(1+\lambda) \quad\left(14 \alpha^{2}-16 \alpha+5\right)-8 \lambda \quad(1-$ $\left.\alpha)^{2}\right] / 32 \beta$, it can be verified that if $\left[(1+\lambda)\left(14 \alpha^{2}-\right.\right.$ $\left.16 \alpha+5)+8 \lambda(1-\alpha)^{2}-2 \gamma \alpha^{2}\right] /\left(8(\lambda-\gamma)(1-\alpha)^{2}\right)<s$ $<1$, then $U_{r}^{A^{*}}-U_{r}^{R *}>0$, otherwise, $U_{r}^{A^{*}}-U_{r}^{R *}<0$. Therefore, if $\left[(1+\lambda)\left(14 \alpha^{2}-16 \alpha+5\right)+8 \lambda(1-\alpha)^{2}-\right.$ $\left.2 \gamma \alpha^{2}\right] /\left(8(\lambda-\gamma)(1-\alpha)^{2}\right)<s<1$, then $U_{r}^{A^{*}}>U_{r}^{R *}>$ $U_{r}^{D^{*}}$, and if $0<s<\left[(1+\lambda)\left(14 \alpha^{2}-16 \alpha+5\right)+8 \lambda\right.$ $\left.(1-\alpha)^{2}-2 \gamma \alpha^{2}\right] /\left(8(\lambda-\gamma)(1-\alpha)^{2}\right)$, then $U_{r}^{R^{*}}>$ $U_{r}^{A *}>U_{r}^{D^{*}}$.

\section{Data Availability}

The data used to support the findings of this study are included within the article.

\section{Conflicts of Interest}

The authors declare that they have no conflicts of interest.

\section{Acknowledgments}

This research was supported by the National Natural Science Foundation of China (Grant no. 71771055), Key Projects of Natural Science of Anhui (Grant no. KJ2019A0519), Project of Natural Science of Provincial Platform (Grant no. 2020WLGH01), and Anhui Social Science Innovation and Development Project (Grant no. 2020CX057).

\section{References}

[1] P. Zhang, Y. He, and X. Zhao, “"Preorder-online, pickup-instore" strategy for a dual-channel retailer," Transportation Research Part E: Logistics and Transportation Review, vol. 122, pp. 27-47, 2019.

[2] China Internet Network Information Center (CNNIC), The $45^{\text {th }}$ China Statistical Report on Internet Development, China Internet Network Information Center (CNNIC), Beijing, China, 2020, http://www.cac.gov.cn/2020-04/27/c_158953547 0378587.htm.

[3] I. Moon, S. P. Sarmah, and S. Saha, "The impact of online sales on centralised and decentralised dual-channel supply chains," European J. of Industrial Engineering, vol. 12, no. 1, pp. 67-92, 2018.

[4] S. Saha, "Channel characteristics and coordination in threeechelon dual-channel supply chain," International Journal of Systems Science, vol. 47, no. 3, pp. 740-754, 2015.

[5] P. He, Y. He, and H. Xu, "Channel structure and pricing in a dual-channel closed-loop supply chain with government subsidy," International Journal of Production Economics, vol. 213, pp. 108-123, 2019.

[6] S. Han, Y. Fu, B. Cao, and Z. Luo, "Pricing and bargaining strategy of e-retail under hybrid operational patterns," Annals of Operations Research, vol. 270, no. 1-2, pp. 179-200, 2018.

[7] Y. Li, G. Li, G. K. Tayi, and T. C. E. Cheng, "Omni-channel retailing: do offline retailers benefit from online reviews?" International Journal of Production Economics, vol. 218, pp. 43-61, 2019.

[8] M. Zhang, C. Ren, G. A. Wang, and Z. He, "The impact of channel integration on consumer responses in omni-channel 
retailing: the mediating effect of consumer empowerment," Electronic Commerce Research and Applications, vol. 28, pp. 181-193, 2018.

[9] W.-H. Liu, X.-Y. Yan, X. Li, and W.-Y. Wei, "The impacts of market size and date-driven marketing on the sales mode selection in an Internet platform based supply chain," Transportation Research Part E: Logistics and Transportation Review, vol. 136, Article ID 101914, 2020.

[10] D. Z. Yu, T. Cheong, and D. Sun, "Impact of supply chain power and drop-shipping on a manufacturer's optimal distribution channel strategy," European Journal of Operational Research, vol. 259, no. 2, pp. 554-563, 2017.

[11] P. He, Y. He, and H. Xu, "Buy-online-and-deliver-from-store strategy for a dual-channel supply chain considering retailer's location advantage," Transportation Research Part E: Logistics and Transportation Review, vol. 144, Article ID 102127, 2020.

[12] G. Li, X. Zhang, S.-M. Chiu, M. Liu, and S. P. Sethi, "Online market entry and channel sharing strategy with direct selling diseconomies in the sharing economy era," International Journal of Production Economics, vol. 218, pp. 135-147, 2019.

[13] S. Moorthy, Y. Chen, and S. S. Tehrani, "Selling your product through competitors' outlets: channel Strategy when consumers comparison shop," Marketing Science, vol. 37, no. 1, pp. 138-152, 2018.

[14] K. Cao, J. Wang, G. Dou, and Q. Zhang, "Optimal trade-in strategy of retailers with online and offline sales channels," Computers \& Industrial Engineering, vol. 123, pp. 148-156, 2018.

[15] K. Pan, Z. Cui, A. Xing, and Q. Lu, "Impact of fairness concern on retailer-dominated supply chain," Computers \& Industrial Engineering, vol. 139, Article ID 106209, 2020.

[16] X.-X. Zheng, Z. Liu, K. W. Li, J. Huang, and J. Chen, "Cooperative game approaches to coordinating a three-echelon closed-loop supply chain with fairness concerns," International Journal of Production Economics, vol. 212, pp. 92-110, 2019.

[17] Z. Liu, X.-X. Zheng, D.-F. Li, C.-N. Liao, and J.-B. Sheu, “A novel cooperative game-based method to coordinate a sustainable supply chain under psychological uncertainty in fairness concerns," Transportation Research Part E: Logistics and Transportation Review, vol. 147, Article ID 102237, 2021.

[18] Q. Zhou, Q. Li, X. Hu, W. Yang, and W. Chen, "Optimal contract design problem considering the retailer's fairness concern with asymmetric demand information," Journal of Cleaner Production, vol. 287, Article ID 125407, 2021.

[19] T. Li, J. Xie, X. Zhao, and J. Tang, "On supplier encroachment with retailer's fairness concerns," Computers \& Industrial Engineering, vol. 98, pp. 499-512, 2016.

[20] R. Yoshihara and N. Matsubayashi, "Channel coordination between manufacturers and competing retailers with fairness concerns," European Journal of Operational Research, vol. 290, no. 2, pp. 546-555, 2020.

[21] L. Zhang, H. Zhou, Y. Liu, and R. Lu, "Optimal environmental quality and price with consumer environmental awareness and retailer's fairness concerns in supply chain," Journal of Cleaner Production, vol. 213, pp. 1063-1079, 2019.

[22] S. Saha and I. Nielsen, "Strategic integration decision under supply chain competition in the presence of online channel," Symmetry, vol. 13, no. 1, pp. 1-20, 2021.

[23] Y. He, H. Huang, and D. Li, "Inventory and pricing decisions for a dual-channel supply chain with deteriorating products," Operational Research, vol. 20, no. 3, pp. 1461-1503, 2020.

[24] X.-M. Zhang, Q.-W. Li, and G.-H. Qi, "Decision-making of a dual-channel closed-loop supply chain in the context government policy: a dynamic game theory," Discrete Dynamic in Nature and Society, vol. 2020, Article ID 2313698, 19 pages, 2021.

[25] I. Moon, Y. J. Jeong, and S. Saha, "Investment and coordination decisions in a supply chain of fresh agricultural products," Operational Research, vol. 20, no. 4, pp. 2307-2331, 2020.

[26] X.-M. Zhang, Q.-W. Li, Z. Liu, and C.-T. Chang, "Optimal pricing and remanufacturing mode in a closed-loop supply chain of WEEE under government fund policy," Computers \& Industrial Engineering, vol. 151, no. 8, Article ID 106951, 2020.

[27] D. Yang, T. Xiao, and J. Huang, "Dual-channel structure choice of an environmental responsibility supply chain with green investment," Journal of Cleaner Production, vol. 210, pp. 134-145, 2019.

[28] H. Huang, Y. He, and J. Chen, "Cross-market selling channel strategies in an international luxury brand's supply chain with gray markets," Transportation Research Part E: Logistics and Transportation Review, vol. 144, Article ID 102157, 2020.

[29] J. Zhang, S. Li, S. Zhang, and R. Dai, "Manufacturer encroachment with quality decision under asymmetric demand information," European Journal of Operational Research, vol. 273, no. 1, pp. 217-236, 2019.

[30] Q. Lu and N. Liu, "Effects of e-commerce channel entry in a two-echelon supply chain: a comparative analysis of singleand dual-channel distribution systems," International Journal of Production Economics, vol. 165, pp. 100-111, 2015.

[31] X. Pu, S. Sun, and J. Shao, "Direct selling, reselling, or agency selling? Manufacturer's online distribution strategies and their impact," International Journal of Electronic Commerce, vol. 24, no. 2, pp. 232-254, 2020.

[32] V. Abhishek, K. Jerath, and Z.-J. Zhang, "Agency selling or reselling? Channel structures in electronic retailing?" Management Science, vol. 62, no. 8, pp. 2149-2455, 2015.

[33] S. Shi, J. Sun, and T. C. E. Cheng, "Wholesale or dropshipping: contract choices of the online retailer and the manufacturer in a dual-channel supply chain," International Journal of Production Economics, vol. 226, Article ID 107618, 2020.

[34] L. Xiao, X.-J. Wang, and K.-S. Chin, "Trade-in strategies in retail channel and dual-channel closed-loop supply chain with remanufacturing," Transportation Research Part E: Logistics and Transportation Review, vol. 136, Article ID 101898, 2020.

[35] Y. Zhang and B. Hezarkhani, "Competition in dual-channel supply chains: the manufacturers' channel selection," European Journal of Operational Research, vol. 291, no. 1, pp. 244-262, 2021.

[36] D. Jia and S. Li, "Optimal decisions and distribution channel choice of closed-loop supply chain when e-retailer offers online marketplace," Journal of Cleaner Production, vol. 265, Article ID 121767, 2020.

[37] Y. Sun, Z. Wang, and X. Han, "Supply chain channel strategies for online retailers: whether to introduce web showrooms?" Transportation Research Part E: Logistics and Transportation Review, vol. 144, Article ID 102122, 2020.

[38] A. Sharma, G. Dwivedi, and A. Singh, "Game-theoretic analysis of a two-echelon supply chain with option contract under fairness concerns," Computers \& Industrial Engineering, vol. 137, Article ID 106096, 2019.

[39] X.-X. Zheng, D.-F. Li, Z. Liu, F. Jia, and J.-B. Sheu, "Coordinating a closed-loop supply chain with fairness concerns through variable-weighted Shapley values," Transportation 
Research Part E: Logistics and Transportation Review, vol. 126, pp. 227-253, 2019.

[40] T.-H. Cui, J.-S. Raju, and Z.-J. Zhang, "Fairness and channel coordination," Management Science, vol. 53, no. 8, pp. 1303-1314, 2017.

[41] F. Qin, F. Mai, M. J. Fry, and A. S. Raturi, "Supply-chain performance anomalies: fairness concerns under private cost information," European Journal of Operational Research, vol. 252, no. 1, pp. 170-182, 2016.

[42] W. J. Allender, J. Liaukonyte, S. Nasser, and T. J. Richards, "Price fairness and strategic obfuscation," Marketing Science, vol. 40, no. 1, pp. 1-25, 2021.

[43] P. Toktaş-Palut, "An integrated contract for coordinating a three-stage green forward and reverse supply chain under fairness concerns," Journal of Cleaner Production, vol. 279, Article ID 123735, 2021.

[44] A. Adhikari and A. Bisi, "Collaboration, bargaining, and fairness concern for a green apparel supply chain: an emerging economy perspective," Transportation Research Part E: Logistics and Transportation Review, vol. 135, Article ID 101863, 2020.

[45] W. Liu, D. Wang, X. Shen, X. Yan, and W. Wei, "The impacts of distributional and peer-induced fairness concerns on the decision-making of order allocation in logistics service supply chain," Transportation Research Part E: Logistics and Transportation Review, vol. 116, pp. 102-122, 2018.

[46] T. Nie and S. Du, "Dual-fairness supply chain with quantity discount contracts," European Journal of Operational Research, vol. 258, no. 2, pp. 491-500, 2017.

[47] G.-D. Liu, T.-J. Yang, Y. Wei, and X.-M. Zhang, "Decisions on dual-channel supply chains under market fluctuations and dual-risk aversion," Discrete Dynamics in Nature and Society, vol. 2020, Article ID 2612357, 13 pages, 2020.

[48] G. Li, L. Li, and J. Sun, "Pricing and service effort strategy in a dual-channel supply chain with showrooming effect," Transportation Research Part E: Logistics and Transportation Review, vol. 126, pp. 32-48, 2019.

[49] D. A. Wuttke, C. Blome, and M. Henke, "Focusing the financial flow of supply chains: an empirical investigation of financial supply chain management," International Journal of Production Economics, vol. 145, no. 2, pp. 773-789, 2013.

[50] S. Zhang and J. Zhang, "Agency selling or reselling: E-tailer information sharing with supplier offline entry," European Journal of Operational Research, vol. 280, no. 1, pp. 134-151, 2020.

[51] S. Du, T. Nie, C. Chu, and Y. Yu, "Newsvendor model for a dyadic supply chain with Nash bargaining fairness concerns," International Journal of Production Research, vol. 52, no. 17, pp. 5070-5085, 2014.

[52] Y.-F. Zhao, Y. Wang, and G.-Q. Shi, “"The impact of consumers" peer-induced fairness concerns on mixed retail and e-tail channels," Discrete Dynamics in Nature and Society, vol. 2020, Article ID 9023470, 15 pages, 2020.

[53] T.-H. Ho, X. Su, and Y. Wu, "Distributional and peer-induced fairness in supply chain contract design," Production and Operations Management, vol. 23, no. 2, pp. 161-175, 2013. 